\title{
ANALISIS DAN PERANCANGAN SISTEM INFORMASI PENJUALAN, PERSEDIAAN DAN PEMBELIAN PADA PT. XYZ
}

\author{
Hendra Alianto \\ Jurusan Sistem Informasi, Fakultas Ilmu Komputer, Binus University \\ Jl. KH. Syahdan No. 9, Palmerah, Jakarta Barat 11480 \\ hendraalianto@binus.ac.id, hendraalianto@yahoo.com
}

\begin{abstract}
Technological development that grows so rapidly and the mounting business competition force a company uses technology that can support the work activities quickly and precisely. At this time, the business processes run by XYZ Company is still done manually which hamper the running business processes. This research aims to analyze the company's current business processes, provide functional recommendations, and design an information system for sales, inventory, and purchasing goods that can support the company's operations. The research uses several methods such as literature study, analysis and design of information systems. The study produces an information system for sales, inventory, and purchases which is able to facilitate the transaction recording, up-to-date, and reliable. The results prove that the new system is able to help the company's performance in running several activities in sales, inventory records, and purchase monitoring to support business processes running more quickly and precisely.
\end{abstract}

Keywords: analysis, design, information sistem, sales, inventory, purchasing.

\begin{abstract}
ABSTRAK
Perkembangan teknologi yang begitu pesat dan persaingan bisnis yang semakin ketat memaksa suatu perusahaan menggunakan teknologi yang mampu mendukung kegiatan aktivitas kerja dengan cepat dan tepat. Pada saat ini, proses bisnis yang berjalan pada Perusahaan XYZ masih dilakukan secara manual yang menghambat kelancaran proses bisnis yang berjalan. Penelitian ini bertujuan menganalisis proses bisnis perusahaan yang sedang berjalan, memberikan rekomendasi serta merancang sistem informasi penjualan, persediaan, dan pembelian barang yang dapat mendukung operasional perusahaan. Metode yang digunakan adalah studi pustaka, analisis dan perancangan sistem informasi. Penelitian ini menghasilkan sebuah sistem informasi penjualan, persediaan, dan pembelian yang dapat memudahkan pencatatan transaksi, up-to-date, dan dapat diandalkan. Hasil penelitian ini membuktikan bahwa sistem yang baru dapat membantu kinerja perusahaan dalam menjalankan aktivitas penjualan, mendata stok barang, dan memantau pembelian sehingga proses bisnis dapat berjalan dengan lebih cepat dan tepat.
\end{abstract}

Kata kunci: analisis, perancangan, sistem informasi, penjualan, persediaan dan pembelian. 


\section{PENDAHULUAN}

Pada era globalisasi sekarang ini, informasi merupakan kebutuhan yang sangat penting bagi kelangsungan berjalannya proses bisnis. Informasi digunakan untuk menilai kinerja dari suatu badan usaha, mengawasi dan mengendalikan jalannya proses bisnis. Oleh karena itu, dibutuhkan penanganan bisnis yang andal. Pengoperasian bisnis yang dilakukan secara manual sudah tidak relevan lagi dalam menangani kebutuhan dan tidak menjawab berbagai permasalahan yang dihadapi perusahaan sehingga dibutuhkan teknologi yang mampu menjawab kebutuhan akan sistem yang terotomatisasi untuk menjalankan proses bisnis, sehingga proses bisnis dapat berjalan lebih cepat, memiliki perhitungan yang lebih akurat serta dapat mendukung keputusan yang tepat sasaran. Pada saat ini, proses bisnis yang berjalan pada Perusahaan XYZ masih dilakukan secara manual. Dengan keadaan usaha yang cukup besar dan omset yang cukup tinggi, perusahaan XYZ mengalami kesulitan, salah satunya pengontrolan jumlah stok yang ada di outlet dan gudang. Tentunya hal ini menghambat kelancaran proses bisnis yang berjalan. Oleh karena itu, dengan penggunaan sistem pencatatan yang lebih sistematis diharapkan nantinya pemilik maupun karyawan Perusahaan XYZ dapat menghemat waktu serta dengan mudah melakukan pencatatan transaksi penjualan dan pembelian serta memantau persediaan jam yang ada. Ruang lingkup analisis sistem yang berjalan dikhususkan pada: (1) Penjualan meliputi pesanan barang dan penjualan barang; (2) Persediaan barang meliputi pencatatan stok barang yang masuk dan keluar di outlet serta di gudang; dan (3) Pembelian meliputi proses pembelian ke supplier.

\section{Kajian Teoritik}

\section{Sistem Informasi Penjualan}

Menurut Kottler (2005, p.23), konsep penjualan mempunyai perspektif dari dalam ke luar. Konsep itu dimulai dari pabrik, berfokus pada produk yang sudah ada, serta menuntut penjualan dan promosi dengan cara keras untuk menghasilkan penjualan yang dapat menghasilkan laba. Sistem informasi penjualan menurut penulis yaitu suatu kegiatan yang meliputi transaksi penjualan barang dan jasa baik secara tunai atau kredit dengan tujuan untuk menghasilkan laba.

\section{Sistem Informasi Pembelian}

Menurut McLeod (2004, p.248), sistem pembelian terjadi dipicu dari adanya transaksi penjualan yang terjadi secara operasional pada perusahaan sehingga mengakibatkan pengurangan inventory yang ada pada perusahaan dan sebelum inventory tersebut persediaannya habis atau mencapai batas persediaan kembali maka bagian pembelian harus menyetok kembali persediaannya. Bagian pembelian memiliki tanggung jawab memilih pemasok yang mana yang akan bekerja sama dalam pengisian kembali persedian dan merundingkan pengaturannya seperti harga dan tanggal pengiriman. Setelah memutuskan pemasok yang akan menyediakan inventory, bagian pembelian akan membuat data pembelian yang akan di berikan kepada pihak pemasok untuk dipenuhi dan barang pesanan pembelian inventory diterima perusahaan.

\section{Sistem Informasi Pesediaan}

Konsep persediaan menurut Warren (2005, p.452) digunakan untuk mengindikasi barang dagang yang disimpan untuk dijual dalam operasi bisnis perusahaan dan bahan yang digunakan dalam proses produksi atau disimpan untuk tujuan itu. Dalam informasi persediaan yang terlibat adalah bagian persediaan yang melakukan pengecekan stok barang dan pengubahan stok barang. 


\section{METODE}

Metode yang digunakan pada penelitian ini diawali dengan studi pustaka dengan mencari referensi pada buku-buku dengan topik sistem informasi dan studi lapangan dengan survei langsung ke perusahaan. Selanjutnya, dilakukan analisis SWOT terhadap sistem berjalan, kemudian melakukan perancangan model sistem informasi berorientasi objek dengan bahasa perancangan UML (Unified Modeling Language).

\section{HASIL DAN PEMBAHASAN}

\section{Hasil Observasi}

Melalui observasi dan pengumpulan data melalui wawancara telah diidentifikasi beberapa masalah yang dihadapi Perusahaan XYZ yaitu: (1) Sulit mencari data transaksi penjualan ketika diperlukan karena berkas nota-nota penjualan yang menumpuk, hilang, dan rusak; (2) Pemilik sulit mengetahui informasi mengenai barang-barang apa saja yang dibeli oleh konsumen; (3) Jumlah stok barang yang ada di outlet dan di gudang tidak diketahui secara real time karena adanya penambahan dan pengurang stok barang yang tidak diketahui. Selain itu, sering terjadi kesalahan dalam perhitungan stok yang ada di outlet dan di gudang; (4) Tidak diketahui stok barang di outlet yang telah habis pada saat pelanggan ingin membeli jam dan tidak diketahui stok barang di gudang yang telah habis jika bagian penjualan meminta pengeluaran jam untuk di berikan ke outlet; dan (5) Pemilik sering terlambat menerima laporan permintaan pembelian jam oleh bagian gudang karena pengecekan barang masih manual sehingga membutuhkan waktu yang cukup lama.

\section{Analisis SWOT}

Analisis SWOT (Strengths, Weaknesses, Opportunities and Threats) yang dilakukan terhadap kondisi perusahaan ditunjukkan pada Tabel 1.

Tabel 1

Hasil Analysis SWOT Dari Penggunaan Sistem Informasi di Perusahaan XYZ

\begin{tabular}{ll}
\hline Strength & (1) $\begin{array}{l}\text { Menghasilkan informasi dan laporan yang dibutuhkan secara cepat, } \\
\text { tepat dan akurat untuk membantu Perusahaan dalam pengambilan } \\
\text { keputusan; }\end{array}$ \\
& (2) Menghadapi permasalahan yang dihadapi sebelumnya. \\
\hline Weakness & (1) Sistem yang digunakan harus sesuai dengan perkembangan \\
& teknologi agar sistem menjadi valid dan up-to-date; \\
& (2) Kekurangan yang ada pada sistem berjalan ini dapat diperbaiki \\
sehingga penggunaan sistemnya dapat lebih maksimal.
\end{tabular}




\section{Pemecahan Masalah}

Solusi yang diusulkan untuk masalah yang dihadapi oleh Perusahaan XYZ diatas yaitu membuat sistem informasi penjualan, persediaan, dan pembelian barang yang mendukung penyimpan data transaksi dan laporan ke dalam database.

Sistem informasi penjualan, persediaan, dan pembelian barang tersebut harus dapat mencatat setiap transaksi yang terjadi secara otomatis sehingga pemilik mengetahui barang-barang apa saja yang telah terjual. Selain itu mencatat setiap penambahan ataupun pengurangan stok sehingga mengurangi resiko kesalahan perhitungan stok.

Sistem informasi tersebut juga harus menggunakan sistem ROP (Reorder Point) sehingga dapat diketahui stok barang yang telah mencapai batas minimum atau stok barang yang telah habis. Lalu sistem harus dapat melakukan pengecekan stok barang yang ada di gudang secara berkala sehingga bagian gudang tidak akan mengalami keterlambatan dalam permintaan pembelian barang ke bagian pembelian.

Analisis kebutuhan informasi terhadap perusahaan XYZ menghasilkan beberapa kebutuhan yaitu: (1) dapat menyediakan informasi mengenai barang yang paling banyak dijual ke pelanggan; (2) dapat menyediakan laporan penjualan, pemesanan, pengeluaran barang dan pembelian secara periodik yang digunakan untuk pengambilan keputusan; (3) memberikan tanda peringatan bagi pengguna sistem jika persediaan barang yang ada di outlet dan di gudang mencapai batas minimum; dan (4) dapat mengetahui sisa persediaan barang yang ada di outlet maupun di gudang.

\section{Sistem yang Diusulkan}

Actor dalam sistem ini ada empat, yaitu Bagian Penjualan, Bagian Pembelian, Bagian Gudang, dan Bagian Admin. Bagian Penjualan mempunyai tiga use case yaitu melayani transaksi pemesanan penjualan, melayani transaksi penjualan, melayani transaksi pemindahan. Bagian Gudang juga mempunyai tiga use case yaitu melayani transaksi pengeluaran, melayani transaksi pemesanan pembelian dan melayani transaksi penerimaan. Bagian Pembelian hanya terlibat dalam use case melayani transaksi pembelian. Bagian Admin terlibat dalam membuat laporan penjualan, membuat laporan persediaan dan membuat laporan pembelian. Untuk lebih jelasnya lihat Gambar 1.

Berikut ini adalah sistem baru yang diusulkan dalam proses penjualan, pengiriman, dan persediaan. (1) Pelanggan yang tertarik membeli jam datang ke outlet dan melakukan penawaran dengan bagian penjualan; (2) Setelah melakukan proses penawaran, terciptalah kesepakatan harga yang ditetapkan bersama; (3) Setelah merasa cocok, pelanggan membeli jam tersebut; (4) Bagian penjualan akan memperlihatkan perlengkapan jam yang dipesan; (5) Pelanggan dapat langsung membayar kepada Bagian Penjualan jika sudah yakin dengan barang yang dibeli; (6) Bagian penjualan akan membuat Transaksi Penjualan berisikan pesanan pelanggan dan jumlah yang dibayar yang diberikan ke pelanggan beserta jam yang sudah dibayar; (7) Pelanggan juga dapat memesan lewat telepon ke bagian penjualan; (8) Lalu bagian penjualan akan membuatkan Transaksi Pemesanan Penjualan; (9) Transaksi Pemesanan Penjualan berisi data pesanan jam beserta nama dan nomor telepon pelanggan; (10) Bagian penjualan akan menginformasikan total pembayaran dan nomor transaksi pemesanan pelanggan; (11) Pelanggan dapat langsung datang ke outlet untuk membayar jam yang dipesan; (12) Setelah melakukan pembayaran bagian penjualan akan memberikan jam tersebut beserta Transaksi Penjualan yang dicetak; (13) Jika stok jam di outlet habis, Bagian Penjualan akan meminta jam kepada Bagian Gudang dengan membuat Transaksi Pemindahan; (14) Setelah menerima Transaksi Pemindahan, bagian gudang akan memberikan jam beserta Transaksi Pengeluaran; (15) Jika stok di gudang sudah habis, bagian gudang akan melakukan Transaksi Pemesanan Pembelian yang diberikan kepada bagian pembelian; (16) Bagian pembelian akan melakukan Transaksi Pembelian ke 
supplier; (17) Bagian gudang melayani Transaksi Penerimaan ketika Pemasok sudah mengantarkan pesanan ke gudang; (18) Setiap bulannya Bagian Penjualan memberikan Data Penjualan kepada Bagian Admin; (19) Setiap bulannya Bagian Gudang memberikan Data Persediaan kepada Bagian Admin; (20) Setiap bulannya Bagian Pembelian memberikan Data Pembelian kepada Bagian Admin; (21) Setiap bulannya bagian Admin akan membuatkan Laporan Penjualan yang diberikan kepada pemilik; (22) Bagian Admin juga akan membuat Laporan Persediaan yang diberikan kepada pemilik setiap bulannya; (23) Bagian Admin juga akan membuat Laporan Penjualan yang diberikan kepada pemilik setiap bulannya. Untuk lebih jelasnya, lihat Gambar 2.

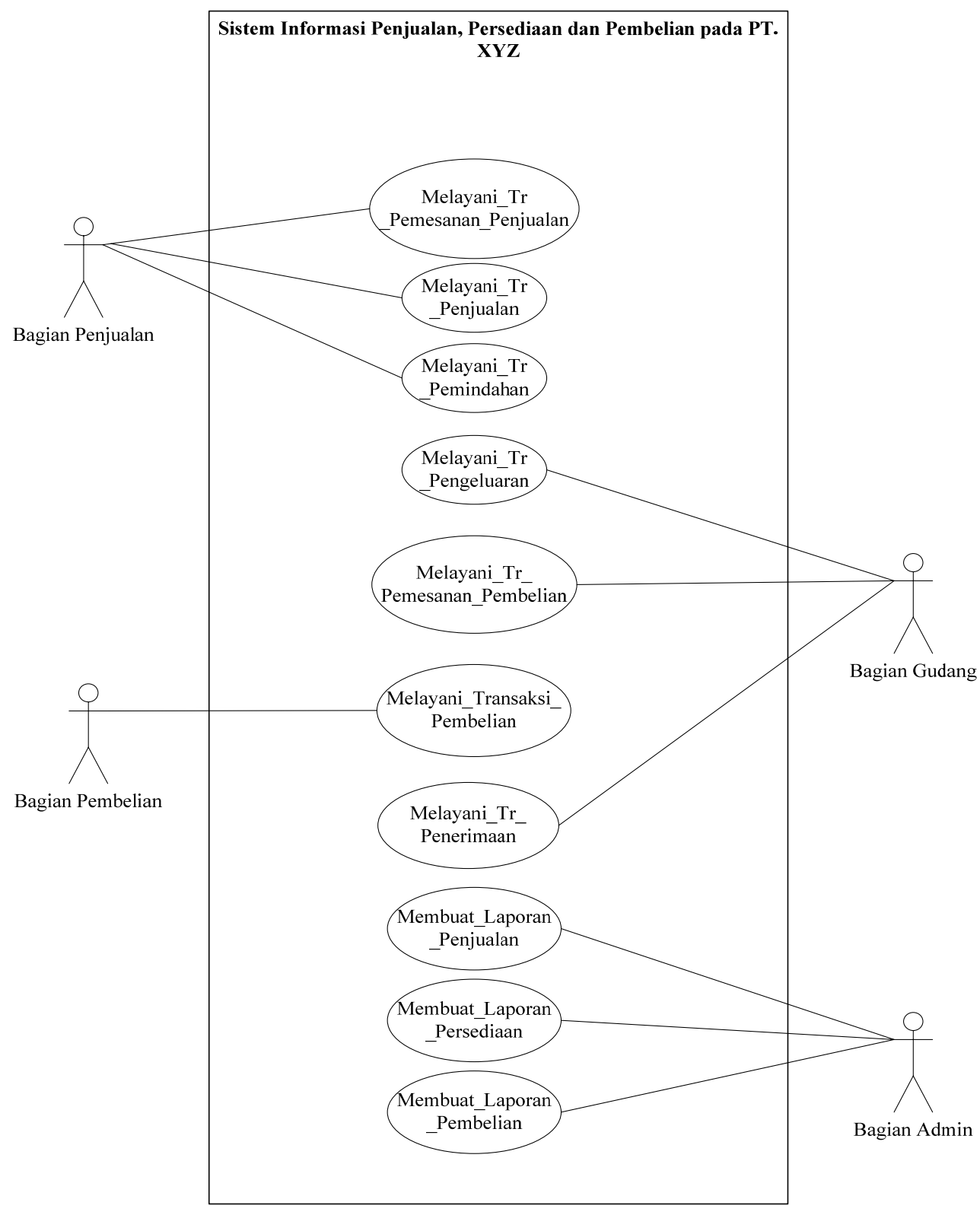

Gambar 1. Use case diagram. 


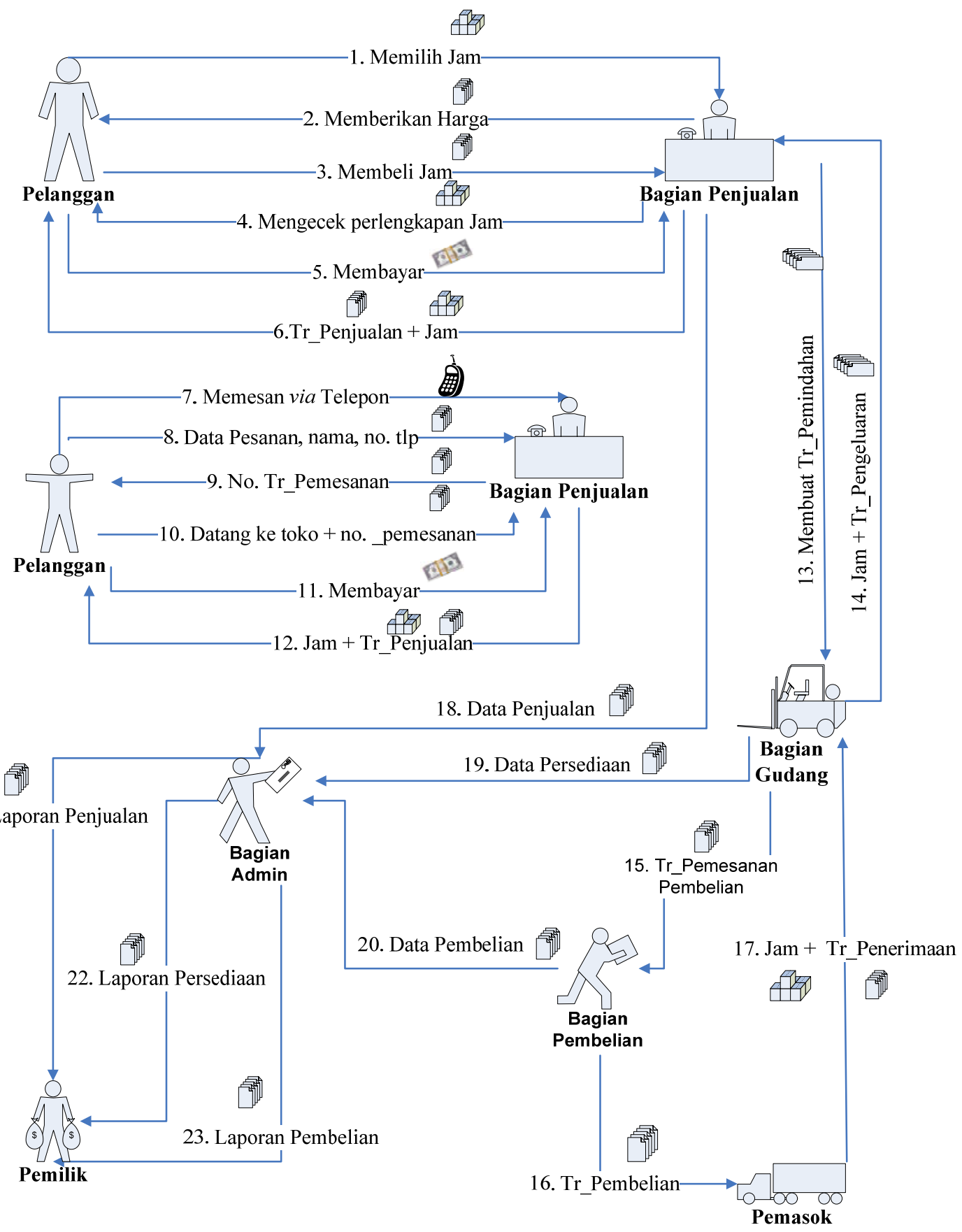

Gambar 2. Rich Picture dari sistem yang diusulkan dalam studi ini.

\section{PENUTUP}

\section{Kesimpulan}

Sistem yang terkomputerisasi ini diharapkan dapat membantu para karyawan Perusahaan XYZ dalam menyelesaikan tugas-tugas operasional penjualan, persediaan barang dan pembelian, serta pengawasan terhadap usaha yang terjadi di outlet. Selain itu dengan adanya sistem informasi 
penjualan, persediaan barang dan pembelian yang diusulkan diharapkan dapat membantu menghasilkan informasi dan laporan yang dibutuhkan secara cepat, tepat dan akurat untuk membantu perusahaan dalam pengambilan keputusan.

\section{Saran}

Untuk melancarkan kegiatan penjualan serta persediaan pada perusahaan disarankan untuk: (1) menyesuaikan sistem yang digunakan dengan perkembangan teknologi agar sistem menjadi valid dan up-to-date; (2) mendapat dukungan dari karyawan untuk penggunaan sistem dan pemilik perusahaan diharapkan untuk dapat menyediakan fasilitas yang diperlukan; dan (3) memperbaiki kekurangan yang ada pada sistem berjalan sehingga penggunaan sistemnya dapat lebih maksimal.

\section{DAFTAR PUSTAKA}

Kottler, Philip. (2005). Manajemen Pemasaran (edisi ke-11, jilid ke-1). (Bambang Sarwaji, terj.). Jakarta: Indeks.

McLeod Jr., R., Schell, G. P. (2004). Sistem Informasi Manajemen (edisi ke-8). (Agus Widyantoro, terj.). Jakarta: Indeks.

McLeod, R., Schell, G.. (2001). Management Information System, $8^{\text {th }}$ Edition. Prentice Hall.

Wilkinson, J.W. (1995). Sistem Akuntansi dan Informasi. (M. Sinaga, terj.). Jakarta: Erlangga. 